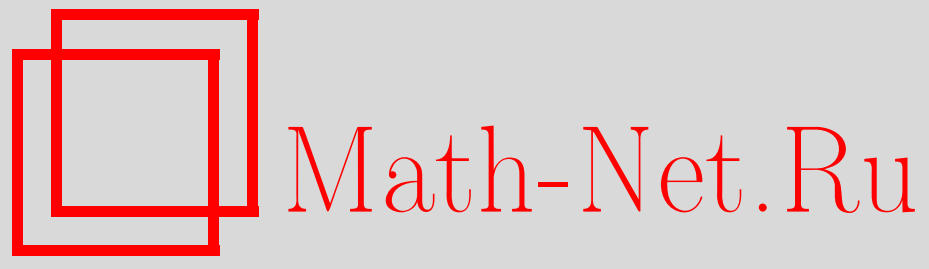

G. P. Chistyakov, F. Götze, On bounds for moderate deviations for Student's statistic, Теория вероятн. и ее примен., 2003, том 48, выпуск 3, 609-615

DOI: https://doi.org/10.4213/tvp275

Использование Общероссийского математического портала MathNet.Ru подразумевает, что вы прочитали и согласны с пользовательским соглашением

http://www . mathnet.ru/rus/agreement

Параметры загрузки:

IP: 34.229 .108 .108

26 апреля 2023 г., 06:09:16

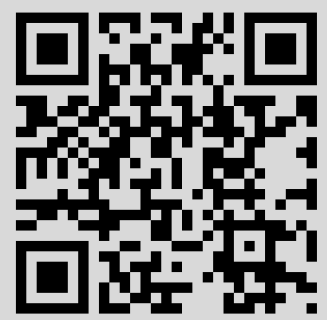


(C) 2003 r. CHISTYAKOV G. P.*, GÖTZE F.**

\section{ON BOUNDS FOR MODERATE DEVIATIONS FOR STUDENT'S STATISTIC ${ }^{1)}$}

Пусть $X_{1}, X_{2}, \ldots$ - независимые случайные величины с нулевыми средними и конечными дисперсиями. В статье доказываются нижние оценки в теореме типа Крамера о больших уклонениях для самонормированных сумм, позволяющие утверждать, что оценки, полученные в [14], точны.

Ключевые слова и фразы: зоны Линника, самонормированная сумма, $t$-статистика, умеренные уклонения, неравномерные оценки.

1. Introduction and results. Let $X, X_{1}, X_{2}, \ldots$ denote independent identically distributed (i.i.d.) random variables such that $\mathbf{E} X=0$ and $0<\sigma^{2}=\mathbf{E} X^{2}<\infty$. Write

$$
S_{n}=\sum_{j=1}^{n} X_{j} \quad \text { and } \quad V_{n}^{2}=\sum_{j=1}^{n} X_{j}^{2} .
$$

Define the self-normalized sum as $S_{n} / V_{n}$, if $V_{n} \neq 0$, and 0 if $V_{n}=0$.

Let $\Lambda(n)$ denote a nondecreasing function satisfying $\Lambda(n) \rightarrow \infty$ as $n \rightarrow \infty$. The interval $[0, \Lambda(n)]$ is called zone of normal convergence if

$$
\frac{1-\mathbf{P}\left\{S_{n}<x \sigma \sqrt{n}\right\}}{1-\Phi(x)} \longrightarrow 1, \quad \frac{\mathbf{P}\left\{S_{n}<-x \sigma \sqrt{n}\right\}}{\Phi(-x)} \longrightarrow 1
$$

uniformly in $x \in[0, \Lambda(n)]$, where $\Phi$ denotes the standard Gaussian distribution function. It is well known, assuming that the condition $\beta=\mathbf{E}|X|^{3}<\infty$ holds, that the BerryEsseen bound implies (1.1) with $\Lambda(n)=(1-\varepsilon) \sqrt{\ln n}$, for $0<\varepsilon<1$. In this case the zone of normal convergence is of logarithmic size and is rather narrow. Consider the condition

$$
\mathbf{E} \exp \left\{\left|X_{1}\right|^{4 \alpha /(2 \alpha+1)}\right\}<\infty
$$

with some $\alpha$ such that $0<\alpha \leqslant \frac{1}{6}$. Yu. V. Linnik [15] (see as well [13]) proved the following result. For any function $\rho(n)$ with $\lim _{n \rightarrow \infty} \rho(n)=\infty$ the relation (1.1) holds with $\Lambda(n)=n^{\alpha} / \rho(n)$. Furthermore, if (1.1) holds with $\Lambda(n)=n^{\alpha} \rho(n)$, then the condition (1.2) is fulfilled. This result of Linnik shows that for deterministically normalized sums the existence of exponential moments is a natural condition for the existence of power type zones of normal convergence.

E. Giné, F. Götze and D. Mason [9] noticed that the tails of $S_{n} / V_{n}$ are uniformly subGaussian in cases when the sequence $S_{n} / V_{n}$ is stochastically bounded. This observation suggests that Linnik type results for self-normalized sums have to hold under conditions considerably weaker than (1.2). Q. M. Shao [21] established that for self-normalized sums Linnik type results hold under the more natural condition of the existence of the third moment $\beta<\infty$.

Let us discuss some results for self-normalized sums related to the CLT and their refinements. Self-normalized sums satisfy the CLT provided that $X$ belongs to the domain of attraction of a normal law ([17], [5]). P. Griffin and D. Mason [10] proved that the condition is necessary in the symmetric case. E. Giné, F. Götze and D. Mason [9] proved that the condition is necessary for nonsymmetric $X$ as well. V. A. Egorov [7] established

* Физико-технический институт низких температур им. Б. И. Веркина НАН Украины, пр. Ленина, 47, 61164 Харьков, Украина; e-mail: chistyakov@ilt.kharkov.ua

** Fakultät für Mathematik, Universität Bielefeld, Postfach 100131, 33501 Bielefeld 1, Germany; e-mail: goetze@mathematik.uni-bielefeld.de

1) The first author supported by DFG GO-420/3-3 in Bielefeld; the second author supported by INTAS 99-00317, RFBR-DFG 99-01-04027. 
necessary and sufficient conditions in the non-i.i.d. symmetric case. These results indicate that self-normalization may improve the limiting tail behavior of sums.

Berry-Esseen bounds of increasing generality and accuracy were obtained in [11], [24], [23], [1], [2]. The paper of V. Bentkus and F. Götze [1] contains bounds which imply, in particular, sufficient conditions for the CLT. The bounds extend to the non-i.i.d. case, see [2]. They obtained the following Berry-Esseen bound. Let $X_{1}, X_{2}, \ldots$ be independent random variables such that $\mathbf{E} X_{j}=0,0<\sigma_{j}^{2}=\mathbf{E} X_{j}<\infty$, and $\beta_{j}=\mathbf{E}\left|X_{j}\right|^{3}$ for all positive integer $j$. Write $B_{n}^{2}=\sum_{j=1}^{n} \sigma_{j}^{2}, A_{n}=\sum_{j=1}^{n} \beta_{j}, L_{n}=A_{n} / B_{n}^{3}$. Then

$$
\begin{aligned}
& \left|\mathbf{P}\left\{\frac{S_{n}}{V_{n}}<x\right\}-\Phi(x)\right| \\
& \quad \leqslant c\left(B_{n}^{-2} \sum_{j=1}^{n} \mathbf{E} X_{j}^{2} \mathbf{I}\left\{\left|X_{j}\right|>B_{n}\right\}+B_{n}^{-3} \sum_{j=1}^{n} \mathbf{E}\left|X_{j}\right|^{3} \mathbf{I}\left\{\left|X_{j}\right| \leqslant B_{n}\right\}\right), \quad x \in \mathbf{R},
\end{aligned}
$$

where $c$ is an absolute constant. Here and in the sequel we denote by $\mathbf{I}\{S\}$ the indicator function of the set $S$. In the case $L_{n}<\infty(1.3)$ has the form $\left|\mathbf{P}\left\{S_{n} / V_{n}<x\right\}-\Phi(x)\right| \leqslant c L_{n}$, $x \in \mathbf{R}$.

Sub-Gaussian type behavior of tails related to self-normalized sums was observed in [16]. E. Giné, F. Götze and D. Mason [9] showed that the tails of $S_{n} / V_{n}$ are uniformly sub-Gaussian in the case when a sequence $S_{n} / V_{n}, n \geqslant 1$, is stochastically bounded. Q. M. Shao $[20]-[22]$ considered large and moderate deviations. Q. Wang and B. Y. Jing [25] proved a bound for symmetric nonidentically distributed random variables. $Q$. Wang and B. Y. Jing [25] derived exponential nonuniform Berry-Esseen bounds for symmetric nonidentically distributed random variables and for identically distributed random variables. G.P. Chistyakov and F. Götze [3] improved their results and considered the even more general situation of independent nonidentically distributed random variables. If $X_{1}, X_{2}, \ldots$ denote symmetric independent random variables with $L_{n}<\infty$, they proved

$$
\left|\mathbf{P}\left\{\frac{S_{n}}{V_{n}}<x\right\}-\Phi(x)\right| \leqslant c \min \left\{1,(x+1)^{3} L_{n}\right\}(1-\Phi(x)), \quad x \geqslant 0,
$$

where $c$ is an absolute constant. Moreover, they established in [4] that (1.4) is a simple consequence of a more general result which shows that the preceding result may hold for wide classes of nonindependent random variables.

Let $X_{1}, \ldots, X_{n}$ be random variables such that the distributions of the random vectors $\left(\delta_{1} X_{1}, \ldots, \delta_{n} X_{n}\right)$ coincide for all values of $\delta_{j}$, where $\delta_{j}= \pm 1, j=1, \ldots, n$, and $L_{n}<\infty$. Then, for all $x \geqslant 0$,

$$
\left|\mathbf{P}\left\{\frac{S_{n}}{V_{n}}<x\right\}-\Phi(x)\right| \leqslant c \min \left\{1,\left(x^{3}+1\right)\left(L_{n}+\mathbf{P}\left\{V_{n}^{2}<\frac{B_{n}^{2}}{2}\right\}\right)\right\}(1-\Phi(x)),
$$

where $c$ is an absolute constant.

Recently B. Y. Jing, Q. Wang, and Q. M. Shao [14] obtained a bound of type (1.4) for general independent random variables. Assume that $X_{1}, X_{2}, \ldots$ are independent random variables with $\mathbf{E} X_{j}=0$ and $0<\mathbf{E} X_{j}^{2}<\infty$ for all $j$. It is proved in [14] that there is an absolute constant $c_{1}\left(c_{1}>1\right)$ such that

$$
\frac{\mathbf{P}\left\{S_{n} \geqslant x V_{n}\right\}}{1-\Phi(x)}=e^{O(1) \Delta_{n, x}} \text { and } \frac{\mathbf{P}\left\{S_{n} \leqslant-x V_{n}\right\}}{\Phi(-x)}=e^{O(1) \Delta_{n, x}}
$$

for all $x \geqslant 0$ satisfying

$$
x^{2} \max _{1 \leqslant j \leqslant n} \mathbf{E} X_{j}^{2} \leqslant B_{n}^{2}
$$

and

$$
\Delta_{n, x} \leqslant c_{1}^{-1}(1+x)^{2},
$$

where, for $x \geqslant 0$,

$$
\Delta_{n, x}=\frac{(1+x)^{2}}{B_{n}^{2}} \sum_{j=1}^{n} \mathbf{E} X_{j}^{2} \mathbf{I}\left\{\left|X_{j}\right|>\frac{B_{n}}{1+x}\right\}+\frac{(1+x)^{3}}{B_{n}^{3}} \sum_{j=1}^{n} \mathbf{E}\left|X_{j}\right|^{3} \mathbf{I}\left\{\left|X_{j}\right| \leqslant \frac{B_{n}}{1+x}\right\}
$$

and $|O(1)| \leqslant c$. 
In the following we shall denote by $\theta$ different real-valued quantities such that $|\theta| \leqslant 1$. The notation $c, c_{2}, c_{3}, \ldots$ will be used throughout for absolute positive constants. By $c$ we denote different constants in different (or even in the same) formulae. The symbols $c_{2}, c_{3}, \ldots$ are used for specific constants.

In this note we shall prove that the bound (1.5) is best possible. To prove this statement we need the following Proposition 1.

Proposition 1. Let $\left\{\beta_{n}\right\}_{n=1}^{\infty}$ be a sequence of real numbers such that $\beta_{n} \geqslant e$ and $\beta_{n} / \sqrt{n} \rightarrow 0$ as $n \rightarrow \infty$. Then there exist i.i.d. random variables $X=X(n), X_{1}, \ldots, X_{n}$ and absolute positive constants $c, c_{2}$ such that $\mathbf{E} X=0, \mathbf{E} X^{2}=1, \mathbf{E}|X|^{3}=(1+$ $\theta / n) 5 \beta_{n} / 3$, and

$$
\begin{array}{cc}
\frac{\mathbf{P}\left\{S_{n} / V_{n}>x\right\}}{1-\Phi(x)} \leqslant \exp \left\{-\frac{c \beta_{n} x^{3}}{\sqrt{n}}\right\}, & 1 \leqslant x \leqslant \frac{c_{2} \sqrt{n}}{\beta_{n}}, \\
\frac{\mathbf{P}\left\{S_{n} / V_{n}<-x\right)}{\Phi(-x)} \geqslant \exp \left\{\frac{c \beta_{n} x^{3}}{\sqrt{n}\},}\right. & 1 \leqslant x \leqslant \frac{c_{2} \sqrt{n}}{\beta_{n}}, \\
\mathbf{P}\left\{\frac{S_{n}}{V_{n}}>x\right\} \geqslant \exp \left\{-\frac{c n}{\beta_{n}^{2}}\right\}, & \frac{c_{2} \sqrt{n}}{\beta_{n}}<x \leqslant \sqrt{n},
\end{array}
$$

for sufficiently large $\sqrt{n} / \beta_{n} \geqslant c$. In addition, for these random variables $X_{1}, \ldots, X_{n}$, the following bounds hold

$$
\frac{1}{2} \frac{\beta_{n}(1+x)^{3}}{\sqrt{n}} \leqslant \Delta_{n, x} \leqslant 2 \frac{\beta_{n}(1+x)^{3}}{\sqrt{n}}, \quad 0 \leqslant x \leqslant \frac{\sqrt{n}}{\beta_{n}}-1,
$$

and

$$
\Delta_{n, x}=\left(1+\frac{\theta}{n}\right)(1+x)^{2}, \quad \frac{\sqrt{n}}{\beta_{n}}-1 \leqslant x \leqslant \sqrt{n} .
$$

We see that for $x \in[0, \sqrt{n}]$ (1.6) obviously holds for the random variables $X_{1}, \ldots, X_{n}$ of Proposition 1. By (1.11) and (1.12), (1.7) is satisfied for $0 \leqslant x \leqslant c \sqrt{n} / \beta_{n}$ with $c<1$. Moreover, by (1.8)-(1.12), we obtain for $X_{1}, \ldots, X_{n}$

$$
\begin{array}{lr}
\frac{\mathbf{P}\left\{S_{n} \geqslant x V_{n}\right\}}{1-\Phi(x)} \leqslant e^{-c \Delta_{n, x}}, & 1 \leqslant x \leqslant \frac{c_{2} \sqrt{n}}{\beta_{n}}, \\
\frac{\mathbf{P}\left\{S_{n} \geqslant x V_{n}\right\}}{1-\Phi(x)} \geqslant e^{c \Delta_{n, x}-c n / \beta_{n}^{2}}, & \frac{c_{2} \sqrt{n}}{\beta_{n}}<x \leqslant \sqrt{n},
\end{array}
$$

and

$$
\frac{\mathbf{P}\left\{S_{n} \leqslant-x V_{n}\right\}}{\Phi(-x)} \geqslant e^{c \Delta_{n, x}}, \quad 1 \leqslant x \leqslant \frac{c_{2} \sqrt{n}}{\beta_{n}}
$$

These bounds show that the result of [14] is sharp.

2. Proof of Proposition 1. Let $\left\{\beta_{n}\right\}_{n=1}^{\infty}$ denote a sequence of real numbers such that $\beta_{n} \geqslant e$ and $\beta_{n} / \sqrt{n} \rightarrow 0$ as $n \rightarrow \infty$. Consider i.i.d. random variables $X, X_{1}, \ldots, X_{n}$ such that

$$
\mathbf{P}\left\{X=-x_{1}\right\}=q, \quad \mathbf{P}\{X=\varepsilon\}=1-\left(2 \beta_{n}^{2}\right)^{-1}, \quad \mathbf{P}\left\{X=2 x_{1}\right\}=p,
$$

where

$$
\begin{aligned}
x_{1} & :=\frac{\varepsilon_{1}}{4}+\frac{1}{2} \sqrt{\frac{\varepsilon_{1}^{2}}{4}+4 \beta_{n}^{2}\left(1-\varepsilon^{2}\left(1-\frac{1}{2 \beta_{n}^{2}}\right)\right)} \\
p & :=\frac{1}{6 \beta_{n}^{2}}\left(1-\frac{\varepsilon_{1}}{x_{1}}\right), \quad q:=\frac{1}{6 \beta_{n}^{2}}\left(2+\frac{\varepsilon_{1}}{x_{1}}\right), \quad \varepsilon_{1}:=\left(2 \beta_{n}^{2}-1\right) \varepsilon .
\end{aligned}
$$

Here the parameter $\varepsilon$ depends on $n$ and is a sufficiently small positive number. We see from the definition of $x_{1}$ that $x_{1}=\beta_{n}(1+c|\theta| \sqrt{\varepsilon})$. It is easy to see that $\mathbf{E} X=0, \mathbf{E} X^{2}=1$, and $\mathbf{E}|X|^{3}=(1+c \theta \sqrt{\varepsilon}) 5 \beta_{n} / 3$. Denote $L_{n}:=\mathbf{E}|X|^{3} / \sqrt{n}$. We assume that $L_{n}$ is sufficiently small, i.e., $L_{n}^{-1} \geqslant c$. 
In the first step let us prove the relations

$$
\begin{aligned}
& \mathbf{P}\left\{\frac{S_{n}}{V_{n}}>x\right\} \leqslant\left(1-c L_{n} x^{3}\right)(1-\Phi(x)), \quad 1 \leqslant x \leqslant c_{3} L_{n}^{-1 / 3}, \\
& \mathbf{P}\left\{\frac{S_{n}}{V_{n}}>x\right\} \leqslant(1-\Phi(x)) e^{-c L_{n} x^{3}}, \quad c_{3} L_{n}^{-1 / 3} \leqslant x \leqslant 2 c_{2} L_{n}^{-1},
\end{aligned}
$$

where $c_{3}$ is a sufficiently small positive absolute number.

Let $x \in\left[1,2 c_{2} / L_{n}\right]$, where $c_{2}$ is a sufficiently small positive number. Consider the event $A_{x}=\left\{S_{n} / V_{n}>x\right\}$ and the event that precisely $j$ of $X_{1}, \ldots, X_{n}$ assume the value $\varepsilon$, that is, $H_{j}=\left\{\mathbf{I}\left\{X_{1}=\varepsilon\right\}+\cdots+\mathbf{I}\left\{X_{n}=\varepsilon\right\}=j\right\}$. Then

$$
\mathbf{P}\left(A_{x}\right)=\sum_{j=0}^{n} \mathbf{P}\left\{A_{x} \mid H_{j}\right\} \mathbf{P}\left(H_{j}\right) \text {. }
$$

By the independence of $X_{1}, \ldots, X_{n}$, we note that

$$
\mathbf{P}\left(H_{j}\right)=\left(\begin{array}{l}
n \\
j
\end{array}\right)\left(1-\frac{1}{2 \beta_{n}^{2}}\right)^{j}\left(\frac{1}{2 \beta_{n}^{2}}\right)^{n-j}, \quad j=0, \ldots, n .
$$

Consider $j$ such that $j_{1} \leqslant j \leqslant j_{2}$, where $j_{1}:=(1-p-q-q / 100) n$ and $j_{2}:=(1-p-q+$ $q / 100) n$. By means of an elementary computation, we obtain

$$
\mathbf{P}\left(A_{x} \mid H_{j}\right)=\sum_{m \in B_{x, j}}\left(\begin{array}{c}
n-j \\
m
\end{array}\right) p_{1}^{m} q_{1}^{n-j-m}
$$

where $p_{1}=q /(p+q)=2(1+\theta \sqrt{\varepsilon}) / 3, q_{1}=p /(p+q)=(1+\theta \sqrt{\varepsilon}) / 3$, and $B_{x, j}:=\{m \in$ $\left.\mathbf{Z}_{+}: m \leqslant n-j, a-3 m>x \sqrt{b-3 m}\right\}$, where $a:=2(n-j)+j \varepsilon / x_{1}$ and $b:=4(n-j)+j \varepsilon^{2} / x_{1}^{2}$. It is easy to see that $B_{x, j}=\left\{m \in \mathbf{Z}_{+}: m \leqslant(a-r) / 3\right\}$, where $r=\left(x^{2}+x \sqrt{x^{2}+4(b-a)}\right) / 2$. Since $r=(b-a)^{1 / 2} x+x^{2} / 2+\theta x^{3} /(b-a)^{1 / 2}$, we finally have, for sufficiently small $\varepsilon>0$,

$$
B_{x, j}=\left\{m \in \mathbf{Z}_{+}: m \leqslant \frac{2(n-j)}{3}-\frac{\sqrt{2(n-j)}}{3} x^{\prime}\right\}
$$

where $x^{\prime}:=x+x^{2} /(2 \sqrt{2(n-j)})+\theta x^{3} /(n-j)$.

In the case $x \in\left[-2 c_{2} / L_{n},-1\right]$ the event $A_{x}:=\left\{S_{n} / V_{n}<x\right\}$ and the formulae (2.3) and (2.5) hold with $B_{x, j}:=\left\{m \in \mathbf{Z}_{+}: m \leqslant n-j, a-3 m<x \sqrt{b-3 m}\right\}$. It is easy to see that $B_{x, j}=\left\{m \in \mathbf{Z}_{+}: 2(n-j) / 3+\sqrt{2(n-j)} x^{\prime \prime} / 3 \leqslant m \leqslant n-j\right\}$, where $x^{\prime \prime}:=$ $|x|-x^{2} /(2 \sqrt{2(n-j)})+\theta x^{3} /(n-j)$.

Let $S_{n^{\prime}}$ be the number of successes in $n^{\prime}$ Bernoulli trials with probability $p_{2}=\frac{2}{3}$ for success. The following result is well known (see [8], [18]):

$$
\begin{aligned}
& \mathbf{P}\left\{S_{n^{\prime}}<\frac{2 n^{\prime}}{3}-\frac{\sqrt{2 n^{\prime}} y}{3}\right\} \\
& =(1-\Phi(y)) \exp \left\{\left(1+\frac{\theta y}{100 \sqrt{n^{\prime}}}\right) \frac{y^{3}}{6 \sqrt{2 n^{\prime}}}\right\}\left(1+\theta \frac{y+1}{100 \sqrt{n^{\prime}}}\right), \\
& \mathbf{P}\left\{S_{n^{\prime}}>\frac{2 n^{\prime}}{3}+\frac{\sqrt{2 n^{\prime}} y}{3}\right\} \\
& =(1-\Phi(y)) \exp \left\{-\left(1+\frac{\theta y}{100 \sqrt{n^{\prime}}}\right) \frac{y^{3}}{6 \sqrt{2 n^{\prime}}}\right\}\left(1+\theta \frac{y+1}{100 \sqrt{n^{\prime}}}\right)
\end{aligned}
$$

for all $y \in\left[0, c_{4} \sqrt{n^{\prime}}\right]$ and $n^{\prime} \geqslant c$.

Assuming $x \in\left[1, c_{3} L_{n}^{-1 / 3}\right]$, let us prove (2.1). Using (2.6) with $n^{\prime}=n-j$ and $y=x^{\prime}$ and Taylor's formula, we easily obtain

$$
\begin{aligned}
\mathbf{P}\left(A_{x} \mid H_{j}\right)= & \Phi(-x)+\frac{x^{3}}{6 \sqrt{2(n-j)}} \Phi(-x)-\frac{x^{2}}{2 \sqrt{2(n-j)}} \frac{1}{\sqrt{2 \pi}} e^{-x^{2} / 2} \\
& +\theta \frac{x+1}{100 \sqrt{n-j}} \Phi(-x)+c \theta \frac{x^{5}}{n-j} e^{-x^{2}(1+\theta x / \sqrt{n-j})^{2} / 2}+\theta \eta
\end{aligned}
$$


(here and in the sequel we denote by $\eta=\eta(\varepsilon)$ a positive quantity which depend on $\varepsilon$ and tends to zero as $\varepsilon \rightarrow 0$ ). Recalling the well-known inequality

$$
\left(x^{-1}-x^{-3}\right)(2 \pi)^{-1 / 2} \exp \left\{-\frac{x^{2}}{2}\right\}<\Phi(-x)<x^{-1}(2 \pi)^{-1 / 2} \exp \left\{-\frac{x^{2}}{2}\right\}
$$

for every $x>0$, we finally get

$$
\mathbf{P}\left(A_{x} \mid H_{j}\right)-\Phi(-x)<-\frac{x^{3}}{4 \sqrt{2(n-j)}} \Phi(-x)+\eta, \quad 1 \leqslant x \leqslant c_{3} L_{n}^{-1 / 3},
$$

for all $j_{1} \leqslant j \leqslant j_{2}$.

Now let us estimate $\sigma_{1}:=\sum_{j=0}^{j_{1}} \mathbf{P}\left(H_{j}\right)$ and $\sigma_{2}:=\sum_{j=j_{2}}^{n} \mathbf{P}\left(H_{j}\right)$. By a well-known inequality (see $[8$, v. 1, Ch. 6 , Section 3$]$ ), we have

$$
\sigma_{1} \leqslant c\left(\begin{array}{c}
n \\
j_{1}
\end{array}\right)\left(1-\frac{1}{2 \beta_{n}^{2}}\right)^{j_{1}}\left(\frac{1}{2 \beta_{n}^{2}}\right)^{n-j_{1}}
$$

Hence, using Stirling's formula, we get, by means of a simple calculation,

$$
\left(\begin{array}{c}
n \\
j_{1}
\end{array}\right)\left(1-\frac{1}{2 \beta_{n}^{2}}\right)^{j_{1}}\left(\frac{1}{2 \beta_{n}^{2}}\right)^{n-j_{1}} \leqslant e^{-c / L_{n}^{2}}
$$

The two last bounds yield

$$
\sigma_{1} \leqslant e^{-c / L_{n}^{2}}
$$

The same bound holds for $\sigma_{2}$.

We now return to formula (2.3). Using (2.9) and (2.10), we deduce from (2.3) the following relation:

$$
\begin{aligned}
\mathbf{P}\left(A_{x}\right)-\Phi(-x)= & \sum_{j=0}^{n}\left(\mathbf{P}\left(A_{x} \mid H_{j}\right)-\Phi(-x)\right) \mathbf{P}\left(H_{j}\right)<-x^{3} \Phi(-x) \sum_{j=j_{1}+1}^{j_{2}-1} \frac{\mathbf{P}\left(H_{j}\right)}{4 \sqrt{2(n-j)}} \\
& +e^{-c / L_{n}^{2}}+\eta<-\frac{x^{3}}{4 \sqrt{2\left(n-j_{1}\right)}} \Phi(-x) \sum_{j=j_{1}+1}^{j_{2}-1} \mathbf{P}\left(H_{j}\right)+e^{-c / L_{n}^{2}}+\eta \\
< & -\frac{1}{16} L_{n} x^{3} \Phi(-x)+e^{-c / L_{n}^{2}}+\eta, \quad 1 \leqslant x \leqslant c_{3} L_{n}^{-1 / 3} .
\end{aligned}
$$

For sufficiently small $\varepsilon$ it follows from (2.11) $\mathbf{P}\left(A_{x}\right)-\Phi(-x) \leqslant-L_{n} x^{3} \Phi(-x) / 32,1 \leqslant x \leqslant$ $c_{3} L_{n}^{-1 / 3}$. As an obvious consequence of this inequality we obtain the assertion (2.1).

Let $x \in\left[c_{3} L_{n}^{-1 / 3}, 2 c_{2} L_{n}^{-1}\right]$. Let us prove (2.2). We deduce from (2.5) and (2.6) that, for $j_{1} \leqslant j \leqslant j_{2}$,

$$
\mathbf{P}\left(A_{x} \mid H_{j}\right) \leqslant\left(1+\frac{x^{\prime}+1}{100 \sqrt{n-j}}\right) \Phi\left(-x^{\prime}\right) e^{x^{\prime 3} /(5 \sqrt{2(n-j)})}+\eta .
$$

Noting that, for $x \in\left[2,2 c_{2} L_{n}^{-1}\right]$ with sufficiently small $c_{2}$ and $j_{1} \leqslant j \leqslant j_{2}$,

$$
\begin{aligned}
\frac{1}{2}\left(x^{2}-x^{\prime 2}\right)= & \frac{1}{2}\left(x-x^{\prime}\right) \cdot\left(x+x^{\prime}\right)=-\frac{x^{2}}{2 \sqrt{2(n-j)}}\left(1+\frac{2 \sqrt{2} \theta x}{\sqrt{n-j}}\right) \\
& \times 2 x\left(1+\frac{x}{4 \sqrt{2(n-j)}}+\frac{\theta x^{2}}{2(n-j)}\right) \leqslant-\frac{x^{3}}{3 \sqrt{2(n-j)}},
\end{aligned}
$$

we get, using (2.8), $\Phi\left(-x^{\prime}\right) / \Phi(-x) \leqslant\left(1-x^{-2}\right)^{-1} \exp \left\{-x^{3} /(3 \sqrt{2(n-j)})\right\}$. Then we obtain from (2.12), recalling the definition of $x^{\prime}$ and choosing $\varepsilon>0$ to be sufficiently small,

$$
\mathbf{P}\left(A_{x} \mid H_{j}\right) \leqslant\left(1+\frac{2 x}{100 \sqrt{n-j}}+\frac{2}{x^{2}}\right) \Phi(-x) e^{-x^{3} /(15 \sqrt{2(n-j)})}
$$


$x \in\left[c_{3} L_{n}^{-1 / 3}, 2 c_{2} L_{n}^{-1}\right]$. Combining this estimate with (2.10) for $\sigma_{k}, k=1,2$, we easily obtain from (2.3)

$$
\begin{aligned}
\mathbf{P}\left(A_{x}\right) & \leqslant\left(1+\frac{2 x}{100 \sqrt{n-j_{2}}}+\frac{2}{x^{2}}\right) \Phi(-x) e^{-x^{3} /\left(15 \sqrt{2\left(n-j_{1}\right)}\right)} \sum_{j=j_{1}+1}^{j_{2}-1} \mathbf{P}\left(H_{j}\right)+e^{-c / L_{n}^{2}} \\
& \leqslant \Phi(-x) e^{-c L_{n} x^{3}} \sum_{j=j_{1}+1}^{j_{2}-1} \mathbf{P}\left(H_{j}\right)+e^{-c / L_{n}^{2}} \leqslant \Phi(-x) e^{-c L_{n} x^{3}}
\end{aligned}
$$

for $c_{3} L_{n}^{-1 / 3} \leqslant x \leqslant 2 c_{2} L_{n}^{-1}$, thus proving (2.2).

The assertion (1.8) of Proposition 1 immediately follows from (2.1) and (2.2). In a similar way we prove the bound (1.9).

The assertion (1.10) is proved using the simple chain of inequalities

$$
\begin{aligned}
\mathbf{P}\left\{S_{n} V_{n}^{-1}>x\right\} & \geqslant \mathbf{P}\left\{S_{n} V_{n}^{-1}=\sqrt{n} \geqslant \mathbf{P}\left\{X_{1}=\varepsilon, \ldots, X_{n}=\varepsilon\right\}\right. \\
& =\left(1-\frac{1}{2 \beta_{n}^{2}}\right)^{n} \geqslant e^{-n / \beta_{n}^{2}}, \quad \frac{c_{2} \sqrt{n}}{\beta_{n}} \leqslant x \leqslant \sqrt{n} .
\end{aligned}
$$

Finally the assertions (1.11) and (1.12) can be verified by a simple calculation, which proves the proposition.

\section{REFERENCES}

1. Bentkus V., Götze F. The Berry-Esseen bound for Student's statistic. - Ann. Probab., 1996, v. 24, № 1, p. 491-503.

2. Bentkus V., Bloznelis M., Götze F. A Berry-Esseen bound for Student's statistic in the non-i.i.d. case. - J. Theoret. Probab., 1996, v. 9, № 3, p. 765-796.

3. Chistyakov G. P., Götze F. Moderate deviations for self-normalized sums. - Preprint 99-48. Bielefeld: Universität Bielefeld, 1999.

4. Chistyakov G.P., Götze F. Moderate deviations for Student's statistic. - Tеория вероятн. и ее примен., 2002, т. 47 , в. 3 , с. $518-532$.

5. Csörgö S., Mason D. M. Approximations of weighted empirical processes with applications to extreme, trimmed and self-normalized sums. - Mathematical Statistics Theory and Applications. Proceeding of the First World Congress of the Bernoulli Society (Tashkent, 1986). V. 2. Utrecht: VNU Sci. Press, 1987, p. 811-819.

6. Efron $B$. Student's $t$-test under symmetry conditions. - J. Amer. Statist. Assoc., 1969 , v. 64 , p. $1278-1302$.

7. Егоров $B$. A. Об асимптотическом поведении самонормированных сумм случайных величин. - Теория вероятн. и ее примен., 1996, т. 41 , в. 3, с. 643-650.

8. Феллер В. Введение в теорию вероятностей и ее приложения. Т. 1. М.: Мир, 1984, $528 \mathrm{c}$.

9. Giné E., Götze F., Mason D. When is the Student $t$-statistic asymptotically standard normal. - Ann. Probab., 1997, v. 25, № 3, p. 1514-1531.

10. Griffin P.S., Mason D.M. On the asymptotic normality of self-normalized sums. Math. Proc. Cambridge Philos. Soc., 1991, v. 109, № 3, p. 597-610.

11. Hall $P$. On the effect of random norming on the rate of convergence in the central limit theorem. - Ann. Probab., 1987, v. 16, № 3, p. 1265-1280.

12. Horváth L., Shao Q. M. Large deviations and law of the iterated logarithm for partials sums normalized by the largest absolute observation. - Ann. Probab., 1996, v. 24, № 3, p. $1368-1387$.

13. Ибрагимов И. А., Лияник Ю. В. Независимые и стационарно связанные величины. M.: Наука, 1965, 524 c.

14. Jing B. Yi., Shao Q. M., Wang $Q$. Self-normalized Cramér type large deviations for independent random variables. - Ann. Probab., 2003 (в печати).

15. Линник Ю.В. Предельные теоремы для сумм независимых величин при учете больших уклонений. I. - Теория вероятн. и ее примен., 1961, т. 6, в. 2, с. 145163. 
16. Logan B., Mallows C., Rice S., Shepp L. Limit distributions of self-normalized sums. Ann. Probab., 1973, v. 1, p. 788-809.

17. Maller $A$. A theorem on products of random variables, with application to regression. - Austral. J. Statist., 1981, v. 23, p. 177-185.

18. Петров В. В. Суммы независимых случайных величин. М.: Наука, 1972, 416 с.

19. Pinelis $I$. Extremal probabilistic problems and Hotelling's $T^{2}$ test under a symmetric condition. - Ann. Statist., 1994, v. 22, № 1, p. 357-368.

20. Shao Q.-M. Self-normalized large deviations. - Ann. Probab., 1997, v. 25, №1, p. 285-328.

21. Shao Q.-M. Recent development in self-normalized limit theorems. - Asymptotic Methods in Probability and Statistics. Ed. by B. Szyszkowicz et al. Amsterdam: Elsevier, 1998, p. $467-480$.

22. Shao Q.-M. A Cramér type large deviation result for Student's $t$-statistic. - J. Theoret. Probab., 1999, v. 12, № 2, p. 385-398.

23. Шарахметов Ш. Неравенство Берри-Эссеена для статистики Стьюдента. - Узб. матем. журн., 1995, № 2, с. 101-112.

24. Slavova $V . V$. On the Berry-Esseen bound for Student's statistic. - Lecture Notes in Math., 1985, v. 1155, p. 355-390.

25. Wang Q., Jing B. Y. An exponential nonuniform Berry-Esseen bound for selfnormalized sums. - Ann. Probab., 1999, v. 27, № 4, p. 2068-2088.

Поступила в редакщию 9.VI.2003

(c) $2003 \mathrm{r}$.

\section{JOHNSON O.*}

\section{CONVERGENCE OF THE POINCARÉ CONSTANT}

Постоянная Пуанкаре $R_{Y}$ для случайной величины $Y$ связывает $L^{2}(Y)$-норму функции $g$ с ее производной $g^{\prime}$. Поскольку разность $R_{Y}-$ D $Y$ неотрицательна и равна нулю, тогда и только тогда, когда $Y$ нормальная случайная величина, то эту разность можно рассматривать как расстояние до нормального распределения. В статье устанавливается наилучшая возможная скорость сходимости этого расстояния в центральной предельной теореме. Кроме того, мы показываем, что $R_{Y}$ конечна для дискретных смесей нормально распределенных величин, что позволяет получить скорость сходимости в центральной предельной теореме в смысле относительной энтропии.

Ключевые слова и фразы: постоянная Пуанкаре, спектральная щель, центральная предельная теорема, информация по Фишеру.

1. Introduction and results. Poincaré (or spectral gap) inequalities provide a relationship between $L^{2}$-norms on functions and their derivatives.

D e f i n it i o n $1.1([3])$. Given a random variable $Y$, define the Poincare constant $R_{Y}$ :

$$
R_{Y}=\sup _{g \in H_{1}(Y)} \frac{\mathbf{D} g(Y)}{\mathbf{E} g^{\prime}(Y)^{2}}
$$

where $H_{1}(Y)$ is the space of absolutely continuous functions on the real line such that $\mathrm{D} g(Y)>0$ and $\mathbf{E} g^{\prime}(Y)^{2}<\infty$.

$R_{Y}$ will not in general be finite, however it will be finite for the normal and other strongly unimodal distributions (see, for example, [10], [8], [6], [5], [11], [3]).

We will exploit various relationships between the Poincare constant and Fisher information.

* Statistical Laboratory, Centre for Mathematical Sciences, Wilberforce Road, Cambridge, CB3 0WB, United Kingdom; e-mail: otj1000@cam.ac.uk 